\title{
Introduction
}

Assumptions about the existence of life stages and developmental sequences permeate our view of the world. Thus, the audience had a good sense of what was meant when Craig McDevitt (2000) spoke, in his opening remarks to the Sixth Annual Counselling Research Conference of the British Association for Counselling (as it then was), of the ability to do research being a significant 'mark of maturity', indicating how the profession was 'coming of age'. At the same conference Mel Ainscow (2000), talked of the professional doctorate in counselling as indicative of a 'maturing' profession; and Jane Speedy (2000) described different 'generations' of counsellor educators. Our understanding of such terms is frequently implicit and unexamined, and it is an aim of the present text to expose them to scrutiny and critique, and to consider their relevance for the professional counsellor.

Counselling and the Life Course introduces counsellors and trainee counsellors to the concept of the life course as a multidimensional and multidisciplinary framework for thinking about clients' lives within and, most particularly, beyond the counselling setting. For over two decades my interest in the idea of life span development and the concept of the life course has been sustained by the belief - reinforced through experience - that everyone has a story to tell. But we do more than tell our story, we live it. In large part, this book is about the importance of this story, and about different ways of conceptualising and telling it. It will be argued that both clients and counsellors can be seen as composing, in the form of a narrative punctuated by transitions and turning points, a life that is both unique and universal, using tools that are largely culturally determined. The book engages with the tension between, on the one hand, recognising age and life stage as rich, significant, but often overlooked, dimensions of difference and, on the other hand, resisting the invocation of frequently implicit age stereotypes and ageist discrimination.

My interest in this field has also been sustained by the belief that counselling can be a potent means of accessing and working with life 


\section{Counselling and the Life Course}

course issues so that, in the words of Studs Terkel (1975), what we live is 'a sort of life' rather than 'a sort of dying'. The impact of both counsellor and client age on the counselling relationship is considered, with different life stages being seen as characterised by distinctive vulnerabilities that are likely to find voice within the counselling relationship. At the same time, the concept of the life course is also used as an integrative framework for considering the commonalities between different life stages, thereby providing a focus for counsellors' consideration of how to draw on their extant skills and expertise when working with clients of a different age and life stage to that with which they are already familiar.

The present text has provided a welcome opportunity to write about the life course specifically for an audience of counsellors and trainee counsellors. My hope is that the concepts and models covered in this book will be both inherently interesting, and also provide useful additions to the theories and frameworks that currently guide your practice. An 'Activity Trail' of structured exercises is interspersed throughout the text in order to encourage reflection on the concepts discussed, and their significance for clients, for yourself, and/or for your counselling practice. My hope is that the book will be of relevance to counsellors irrespective of their particular theoretical stance. However, as most of my teaching is with students working within the person-centred approach, it may be that a bias towards this perspective can be discerned.

In this book I build on some of my previous publications in the field - notably a chapter in the Handbook of Counselling Psychology (Woolfe et al., 2003) and another, written jointly with Ray Woolfe, in the Handbook of Counselling (Palmer and McMahon, 1997). My book, Life-span Development: Frameworks, Accounts and Strategies (Sugarman, 2001) complements the present text by, for example, discussing the work of several theorists in greater detail, and also considering other topics, such as research methodology, that are not dealt with here at all.

Léonie Sugarman

May 2003 